\title{
Project Based Learning over Traditional Method of Language Teaching: A Quasi Experiment Design in EFL Classrooms
}

\author{
Rozina Somani, Meher Rizvi \\ Aga Khan University Institute for Educational Development \\ Pakistan
}

\begin{abstract}
In the current academic conditions in Pakistan, many students struggle in acquiring mastery over EFL as they receive minimal opportunity to practice language in the real world. A student-centered instruction method is needed to be introduced that places students in contextualized, realistic, problem solving environment of language learning. Project based learning (PBL) is a growing concept globally, however, empirical research on PBL are scarce in English Language instruction methods and nearly nil in the context of Pakistan.

Adopting a quasi-experiment design, the study explored effect of PBL on the writing skills of Grade 8 students in two private schools of Karachi focusing on narrative writing. PBL was introduced to the Intervention Group $(n=28)$ while control group $(n=19)$ was taught with the traditional method (TM) of teaching language. A modified version of Writing Assessment Measure (WAM-R) was adapted as the data collection instrument. Scores on WAM-R during pre-test presented low and similar ( $p>0.05)$ ability of the entire sample $(n=47)$. However, participants of $I G$ showed significant improvement $(p=0.00, r=0.5)$ inferring a prominent effect of PBL on their writing skills. Analysis at the lower cognitive domains revealed improvement in the performance of both the groups inferring both $T M$ and PBL facilitated students. On the contrary, IG showed $70 \%$ improvement in higher cognitive domains demonstrating a clear edge over their CG counterparts (15\% improvement). It is evident from the results that the IG was able to produce better results as it was provided with ample opportunities to recall, understand, and apply and even create a coherently written text using their rhetoric knowledge.
\end{abstract}

\section{Introduction}

Pakistan in general has witnessed an imperious spread of English in many spheres of life, English language holds linguistic power over other languages because of its increasing use in the government, media, industries and other sectors. Moreover, learning English as a foreign language (EFL) has become essential to the social and economic progress of an individual [1]. One of the core factor that students in Pakistan are less motivated towards learning English as a foreign language is the ineffective teaching and learning environment [2].

Upon evaluating the current academic conditions, many students who are exposed to English as their medium of instruction do not use it outside of the school. In Pakistan, students struggle with developing language skills (listening, reading, speaking and writing) whereas writing suffers the most, as students rarely produce original write-ups of their own [1], [2] Students are exposed to grammar and vocabulary in isolation with its practice, the concepts learnt in a language class stay in the class. Thus, students flounder while acquiring mastery in English as a foreign language which has impacts on their high school studies, future academic goals and career opportunities

It is generally accepted that, writing is a strong form of communication needed for an individual to fully participate in society and even contribute to the economy [3]. In language classes, students may learn about the mechanics and strategies to write; however, it is equally important that students are aware when and how to apply their knowledge of language, specifically in writing. It is crucial that EFL instruction methods in Pakistan must come out of Traditional Method of teaching EFL that involves mere transmission of grammar rules. The significance of the undertaken study is pronounced by the philosophy of PBL approach to language teaching and learning; and specifically targets writing skills, which are a more visible product and significant as a skill [3]

The solution to the above mentioned issues can be pursued in the philosophy of John Dewey (1938) who advocates the concept of "Learning by Doing", where knowledge is constructed when a student actually applies it in his/her social and cultural context [4]. Teaching and learning of EFL requires a strong instruction method that simplifies the process and provides opportunities to 'learn by doing'. PBL is a powerful instruction method under the umbrella of student centered leaning that places students in contextualized, realistic, problem solving environment of language learning. The pedagogical 
shift can bring positive impact on a student's future academic and career goals. PBL provides an efficient way of integrating the four skills (listening, reading, speaking and writing) of language, and there is not a fixed pattern or sequence that is followed in a project. Although a project usually starts from reading and listening skills, the final product is presented using speaking or writing skills [5].

\section{Defining PBL}

The roots of Project Based Learning (PBL) meet with John Dewey's philosophy of "learning by doing" and is also reflected in the theories of constructivism [6], [7] Within the framework of PBL, students are provided with opportunities to work on projects that are relevant to the real world, besides involving investigation, conversations and collaboration with peers. The process encourages students to construct their new knowledge by engaging in meaningful complex project tasks and also offers social learning platforms [6], [8], [9], [10], [11]. Furthermore, PBL captivates students' interest and promotes students' engagement by offering a diverse range of real life working projects that takes care of the students' choices as well [8].

Learning by doing can be explicitly achieved through PBL. Proponents of PBL say that when students investigate and seek solutions to problems, they acquire a deeper understanding of the key principles [9]. The essential design elements of PBL includes sustained inquiry, challenging problem, authenticity, student's voice and choice, critique and revision, and a public product [12].

Projects involve two core concepts: production and complexity. It is equivalent to creating something which is actually related to the students' world and imparting skills in students which they will need in real life while working on projects [13]. PBL must not be equated with in-class group work or other task based activities, as it is certainly more than that. It is a versatile vehicle that can be used for integrated language learning and can prove to be feasible option for language teachers in diverse instructional settings. In the light of the stated problem, the study aims to witness the effectivity of PBL as an instruction method on the writing skills [14].

PBL was introduced in the discipline of second language learning about three decades ago. Moreover, it was perceived as an opportunity for the langauge learners to recycle their language knowledge in the natural context [15]. PBL's challenging investigation format does not keep a student to a lower level of cognition; it motivates a student to climb towards the higher cognition goals like analyzing, evaluating and even creating. Work on Bloom's Taxonomy by Marzano and Kendall (as cited in Jacobson \& Lapp) suggests that when a student's personal experiences and knowledge about the writing conventions are activated in the classroom, the approach becomes more than an instrumental value to enhance higher order thinking of the students [16]. When appropriately implemented, PBL methodology can bring the students' voices and choices in written expression upfront by engaging them in challenging and meaningful tasks that permit them to learn by providing and receiving feedback in group based projects. The approach can trigger their higher order cognitive skills, leading towards proficiency improvement in their writing skills [12].

Work of Thomas [9] takes an explicit approach in defining PBL, his work on explaining the five criterion that are a must in a project are cited by mostly all the proponents of PBL [6], [10].

i) Projects are central to curriculum, not peripheral.

ii) Projects have a driving question.

iii) Projects involve constructive investigation.

iv) Projects are student-driven to some significant degree.

v) Projects are realistic.

Knowing the benefits associated with PBL, it is to be understood that PBL is not the ultimate goal for teaching instruction, but it is a pragmatic way to reach the goal which is to prepare students for the life outside school [13]. PBL is a growing concept globally, however, empirical research on PBL are scarce in English Language instruction methods [15] and nearly nil in the context of Pakistan. The undertaken study aims to pronounce results in the context of Pakistan on the affectivity of PBL in English language learning by focusing on narrative writing skills.

\section{Literature Review}

Theorist trace back PBL to the philosophy of Confucius and Aristotle, who proclaimed the idea of learning by doing, to Socrates' model of inquiry and critical thinking. In the $20^{\text {th }}$ century, various philosophers like Dewey (1938) and Rousseau (1979) questioned the traditional methods of teaching that included amassing academic knowledge and expecting learning to occur by osmosis [4][17]. These theorists proposed the concept of cognitive constructivism (Dewey, 1938; Piaget 1954) and pleaded to rejuvenate the teaching methods so that the child became the center of leaning and he/she is expected to be engaged in his/her own knowledge building process[4][18]. A nuanced demonstration of constructive view of education, child-centered learning, school's transformation [13] and a step towards progressive education [10] is possible through Project Based Learning. With this framework, students work as custodians of their own 
knowledge and learning process, besides gaining the skills that are needed for the $21^{\text {st }}$ century.

Scrutinizing the traditional model of instruction, it is seen as, presenting a piece of information to the learner by a teacher and considering the activity of the learner as a vehicle for transmitting the information to the head of a learner. The transmission of knowledge infers that learning only occurs when information is processed by the learner in his head. On the contrary, constructivist view learning as situated within a context where the content of the information serves as a supporting role and learning occurs when the learner him/her self-constructs the knowledge in a specific context where he/she is situated [7].

To bring about a shift from the traditional model of instruction to the learner centered model of instruction that organizes learning around an individual rather than the subject-content, an effective instruction method is needed. The method that places students in the center of the learning, nominating them as in-charge of their own knowledge construction and allowing them to interact with the environment and peers, brings in the element of social learning; thus producing the understanding of the knowledge in their own unique way, leading towards self-awareness of learning and knowing [6].

Within the framework of PBL, students are provided with opportunities to work on projects that are authentic, relevant to the real world; besides involving investigation, conversations and collaboration with peers. The process encourages students to construct their new knowledge by engaging in meaningful complex real life projects in social learning environment [6], [8], [12]. Another dominant view of constructivism is the way cultural and social context is embedded in the cognition process, pronouncing learning is not something stored in the head but is distributed in the social environment. It is like making sense of the world around you while engaging in knowledge building [19]. Furthermore, PBL captivates students' interest and promotes students' engagement by offering a diverse range of real life working projects that takes care of the students' choices as well [8]. MetaCognition is deemed as an important implication of the constructivist view. A surface level of content knowledge and understanding is easy to attain, such as memorization of parts of speech in grammar. Alongside the surface level, knowledge is sufficient to reproduce the gist of the content, but the unconnected knowledge does not become inert knowledge for a learner and henceforth it is easily forgotten [20].

The recent literature debates on the critical role of the teacher in deciding the optimal guidance to be provided to the learners in child-centered instruction methods [20]. The debate remains prominent in declaring how much to provide as background knowledge to students and how much to allow them to explore on their own. Whereas, some studies agree that the level of guidance depends upon the learner and the content they desire to master but disagree on what is labelled as a minimal or optimal guidance [21]. We believe that consideration of the multiple intelligences of learners is also crucial to examine while deciding on the optimal instruction. Proponents of constructivist theories also emphasis on constructing a public entity, whether it's a sand castle on a beach or the theory of the universe, showing acquaintance of knowledge as an active engaging process in a context [22].

While engaged in projects, students interpret and articulate information rather than communicate factual information; this process takes them from lower cognitive levels (remembering, understanding, and applying) to higher cognitive levels of analyzing, evaluating and even creating. Furthermore, group work in particular provides opportunity for students to develop social skills such as planning, communication, collaboration and initiation [7], [9]. Additionally, PBL is linked with the idea of cognitive apprenticeship, where students work on the same ground they would actually work on in real life [9]. Understanding the core of how learning occurs and going back to the challenges teachers face in engaging students in active learning process, Project Based Learning (PBL) comes as a panacea for the situation.

Writing is a strong form of communication that is needed for an individual to fully participate in society and even contribute to the economy [3]. In language classes, students may learn about the mechanics and strategies to write; however, it is equally important that students are aware when and how to apply what they know about language, specifically in writing. Moreover, theories of language acquisition demand the opportunity for the learners to practice the language in the real context, since superficial exposure to grammar and vocabulary does not ensure an in-depth understanding and internalization of language.

PBL is viewed as a mandate for school transformation [13] and a model of progressive education [10]. On the other hand, there are also questions raised on its practical application in a situation where teachers' belief system is different to PBL's ideology. This creates conflict, which takes time to resolve. The other delimmas include the amount of time to be devoted on projects that are justifiable, and do not compromise the effectivity of the curriculum. Are correct answers very much required at the end of the project? And most importantly, how much direction and knowledge dissemination is required on a teacher's part? [9]. Advantages of PBL are envisaged to be more than the challenges, and theoretically proves to be an effective model for student learning outcomes. The study aims to witness its effectivity in the context of Pakistan, particularly in the area of English language writing skills. 


\section{Quasi experiment design}

Quasi Experiment (between-groups) design required intervention (IG) and control groups (CG) for the study. Two intact grade 8 classes of same school system located in the same locality were recruited as research groups. PBL (independent variable) of the study was introduced as an instructional pedagogy to IG to observe the effect on the writing skill (dependable variable) of the students. Whereas the CG was taught via traditional instruction method (TM) for teaching writing skills.

\subsection{Sample Selection}

Two intact Grade 8 classes from two private schools belonging to same school system were selected with Intervention Group $(n=29)$ and Control Group $(n=19)$. Baseline survey results were conducted to ensure participants of both the groups matched on all the social factors (age, background, gender ratio); moreover, past year's academic results were also analyzed to ensure similar caliber of both the groups in language. Table 1 summarizes the demo demographic characteristics of Participants.

Table 1. Demographic characteristics

\begin{tabular}{lccc}
\hline & $\begin{array}{c}\text { Age } \\
\text { Mean }\end{array}$ & \multicolumn{2}{c}{$\begin{array}{c}\text { Gender Ratio } \\
\text { No of participants (\%) }\end{array}$} \\
\cline { 2 - 4 } & & Female & Male \\
\hline CG (n=19) & 13.84 & $7(36 \%)$ & $12(63 \%)$ \\
\hline IG (n=28) & 13.64 & $14(50 \%)$ & $14(50 \%)$ \\
\hline $\begin{array}{l}\text { Total } \\
(\mathbf{n}=\mathbf{4 7})\end{array}$ & 13.72 & $21(45 \%)$ & $26(55 \%)$ \\
\hline
\end{tabular}

\section{Data Collection Instrument: WAM-R}

Writing Assessment Measure (WAM) was adapted [3] and modified (WAM-R) to be used as the data collection instrument. WAM is an analytical based scoring tool targeting the written expression domain, including ideas development, vocabulary, sentence structure and grammar, spelling, punctuation and handwriting. A modified version of Writing Assessment Measure (WAM-R) was adapted as the data collection instrument. The effect of intervention was measured on overall writing skills as well as on the lower cognitive levels (LCDs) and higher cognitive levels (HCDs) of language learning. The assessment tool evaluated eight elements of writing and covered all the cognitive levels of Bloom's Taxonomy, namely: knowledge, understanding, applying, analyzing, evaluating, and creating. The not so relevant measure such as handwriting was eliminated. Modifications in WAM-R are summarized in Table 2.
There are 12 elements of language that have been measured using WAM-R (see Appendix A) where each element of language corresponds to a cognitive level. WAM-R scores element of language on a scale of 1 to 4 , with 4 being the highest. Each score was supported with a qualitative remark. Besides focusing on the vocabulary and sentence structure and grammar (mechanics of writing), WAM-R also focuses on how a student formulates an idea by reading a prompt and subsequently develops that idea into a coherent text (rhetoric knowledge).

Table 2. Modifications in WAM

\begin{tabular}{|c|c|c|}
\hline $\begin{array}{c}\text { Cognitive } \\
\text { Level }\end{array}$ & $\begin{array}{l}\text { Element in } \\
\text { Language }\end{array}$ & $\begin{array}{c}\text { Modification } \\
\text { in WAM }\end{array}$ \\
\hline Not Applicable & Hand writing & Eliminated \\
\hline Remembering & Spelling & Retained \\
\hline \multirow[t]{2}{*}{ Understanding } & Punctuations & Retained \\
\hline & Comprehension & Created \\
\hline \multirow[t]{2}{*}{ Applying } & $\begin{array}{l}\text { Sentence } \\
\text { Structure and } \\
\text { Grammar }\end{array}$ & Retained \\
\hline & Vocabulary & Retained \\
\hline Analysing & $\begin{array}{l}\text { Overall } \\
\text { Structure and } \\
\text { Organisation }\end{array}$ & Retained \\
\hline Evaluating & $\begin{array}{l}\text { Evaluating } \\
\text { Appraising/ } \\
\text { Critical } \\
\text { Thinking }\end{array}$ & Created \\
\hline Creating & Ideas & Retained \\
\hline
\end{tabular}

\subsection{Reliability measure of WAM-R}

A high reliability value of 0.934 was found for 8 items on WAM-R. The reliability signifies that the WAM-R constructs correlate highly with each other and it can measure a single underlying dimension.

\section{Data Collection Methods}

A Pre-test was conducted with $\mathrm{IG}$ and $\mathrm{CG}$ participants, where students were asked to respond to any one of the prompts as mentioned in Appendix A. Students' writings were evaluated by the researcher and a co-evaluator on WAM-R and scores were inserted in SPSS.

Intervention phase was the actual time to manipulate the independent variable (Instruction method) in both the groups. To conduct a controlled experiment, simultaneous teaching at both the groups was opted. The content of the lesson in each class was the same; following bench marks of English Writing competency adopted from National Curriculum of Pakistan [24] but the method of delivery was obviously different. In the control group, usually text books were used to read and understand the content, 
there were rarely any group activities Intervention Group was made engaged with the project through out.

The Project. The intervention group was made into six groups from the first session and were informed about development of the project at the end of the month. Their project was to "develop story books for Grade 5 students in their own school". The sessions progressed by providing facilitation to the students on different content areas of writing, integrating these with the PBL requirements. Additionally, students were made custodians of their own work by asking them to maintain the progress file of their group work. Students placed their brainstormed ideas, class work sheets, and the drafts of their stories in that file.

Post-test. Upon completing eight hours of instruction in both the groups, spread over a period of four weeks, post-test was scheduled which would eventually assist in determining the effect of the change in the instruction method. Post-test was administered in the same way it was done in pre-test. Post-test included prompts of similar difficulty as it was in the pre-test, and students were asked to pick any of the one prompts and write their response. Subsequently, the students' responses were evaluated by me and my co-evaluator independently. After reaching on mutually agreed scores, these were entered in SPSS.

\section{Method Limitations}

The study aimed at revealing the effectiveness of Project Based Learning on the writing skills. However, it focused on only one kind of writing, i.e. narrative. Although, elements of writing could be found similar in other styles of writing such as expository and descriptive but were not technically covered during the intervention. Controlling extraneous factors such as students' motivation, personal inclination towards reading and writing, and parental support offered in writing was beyond the researcher's realm. Intervention for a longer period of time (say for a term) would have generated more real insights on PBL as an effective instruction method, mainly because of the time available to review students' drafts and provide feedback.

\section{Analysis}

Descriptive analysis was conducted using measure of central tendencies (mean and medium), measure of dispersal (standard deviations), frequency charts and distribution tables. The information was further used to compare overall pre and post-test of IG and CG and also within the cognitive levels. Inferential analysis was applied in order to understand the effect of the intervention and observe the effect across various cognitive levels. Results of Kolmogorov-Smirnov (K-
S) test for control group [D (19) $=0.23, \mathrm{p}<0.05]$ and intervention group [D $(28)=0.13, \mathrm{p}<0.05]$ declared data as non-normal. Therefore, the difference of instruction method on the writing skills of grade 8 students was measured through Mann-Whitney (U) test. All effects will be reported at 0.05 level of significance.

\subsection{Overall comparison of pre-test scores}

Descriptively analyzing pre-test scores of IG and $\mathrm{CG}$, it was found that IG $(\mathrm{M}=11.07, \mathrm{SD}=4.064)$ performed better than $\mathrm{CG}(\mathrm{M}=9.79, \mathrm{SD}=2.820)$ with statistically insignificant difference ( $\mathrm{U}=$ $225.500, z=-0.928 p>0.05)$. It was also found that 8 is the most reoccurring score in both IG and CG.

The highest scores were found to be 23 and 17 in IG and $\mathrm{CG}$ respectively. On average, the score on the pretest was found to be $10.55(\mathrm{SD}=3.634)$. Here, high values of standard deviation values signified prescores values as being disperse. Sixty five percent of the students have scores below ten points on WAM-R inferring that both the groups possessed very low and basic competencies of narrative writing skills.

\subsection{Overall comparison of post-test scores}

Once the intervention phase was completed, it was important to conduct a post-test that could establish the effect of PBL as an intervention on the writing skills of the students. Post-test showed improvement in overall scores for both groups depicting that both PBL and TM have made an effect on the narrative writing skills of the students. However, it is important to note that the students of IG have showed noticeable progress $(\mathrm{M}=18.07$, SD $=6.104)$ on the post-test as compared to their CG counterparts $(\mathrm{M}=11.95, \mathrm{SD}=5.437)$ with a statistically significant difference $(\mathrm{U}=105.000, \mathrm{z}=$ $3.507 \mathrm{p}=0.00$ ). Additionally, the participants of $\mathrm{CG}$ have raised their maximum score from 17 to 29 however IG has raised their maximum score from 23 to 31 . Figure 1 illustrates the difference of scores in pre and post-test revealing the significant effect of PBL on narrative writing skills of the IG participants.

\subsection{Performance on Lower Cognitive Domains (LCDs)}

LCDs include knowledge, understanding, and applying thus covering the five elements of language namely spelling, punctuation, comprehension, vocabulary, and Grammar. Summing up both groups' performance on a lower cognitive level, it is evident that IG and CG maintained a similar performance in the pre-test, where the difference was not statistically significant $\mathrm{U}=222.500, \mathrm{z}=-1.039, p>0.05)$. However, both IG and CG demonstrated 
improvement in the LCDs in the post-test inferring that both TM and PBL method facilitated the progress. It was also seen that the performance of IG participants on LCDs improved prominently and was statistically significant through PBL $(U=110.500, z$ $=-3.398, p=0.001$ ) with a medium effect size of 0.49 $\sim 0.5$. PBL facilitated LCDs to a greater extent where IG was able to show $61 \%$ improvement. Figure 2 illustrates the difference in mean scores at each cognitive domain of IG before and after the intervention. On the other hand, participants of CG have shown only $28 \%$ improvement on LCDs signifying TM also somewhat facilitated improvement on lower cognition (see Figure 3)

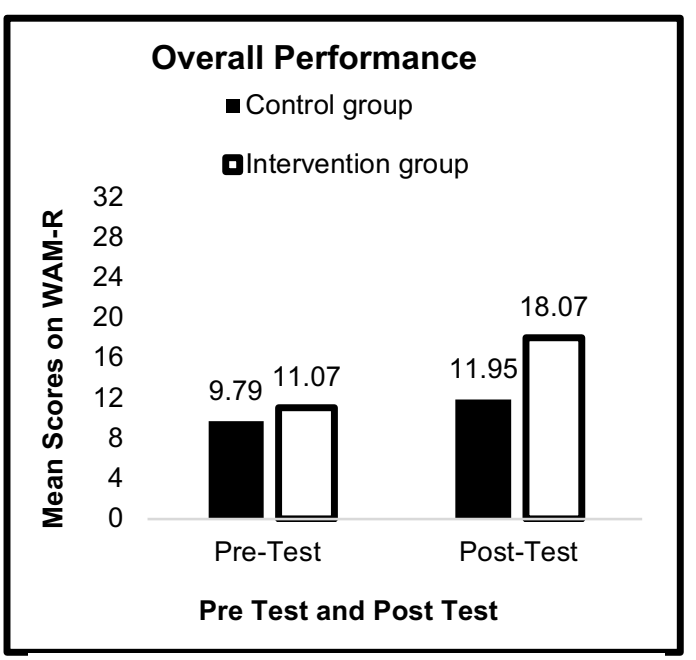

Figure 1. Overall performance of IG and $\mathrm{CG}$ in pre and post-tests

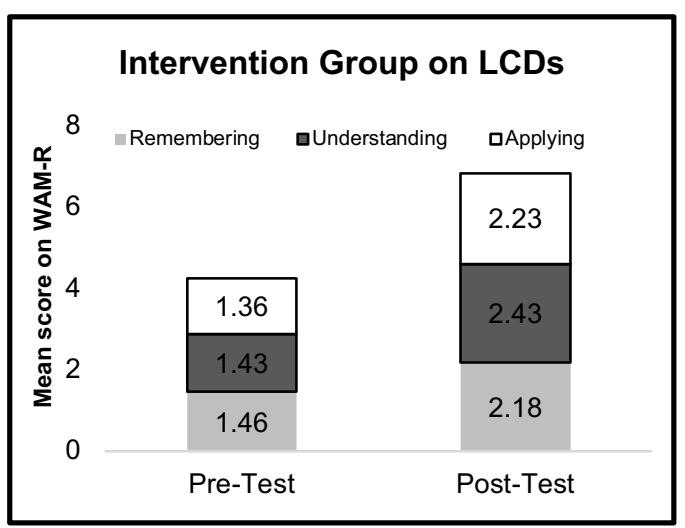

Figure 2. Performance of IG on LCDs

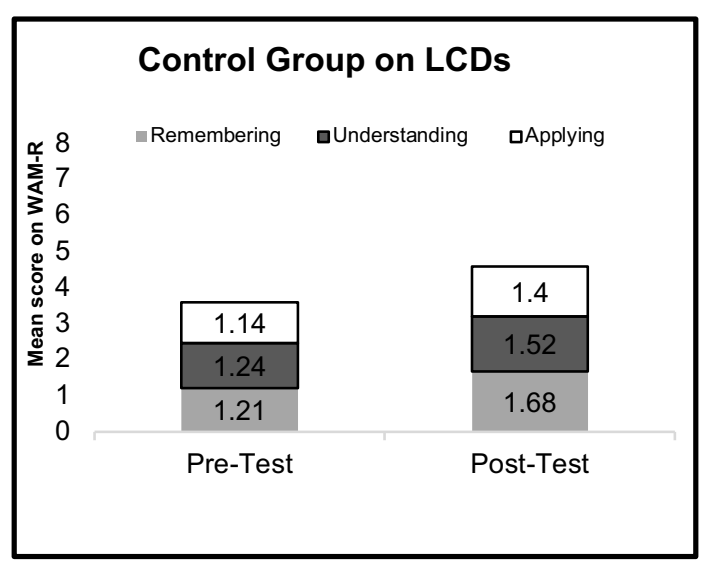

Figure 3. Performance of CG on LCDs

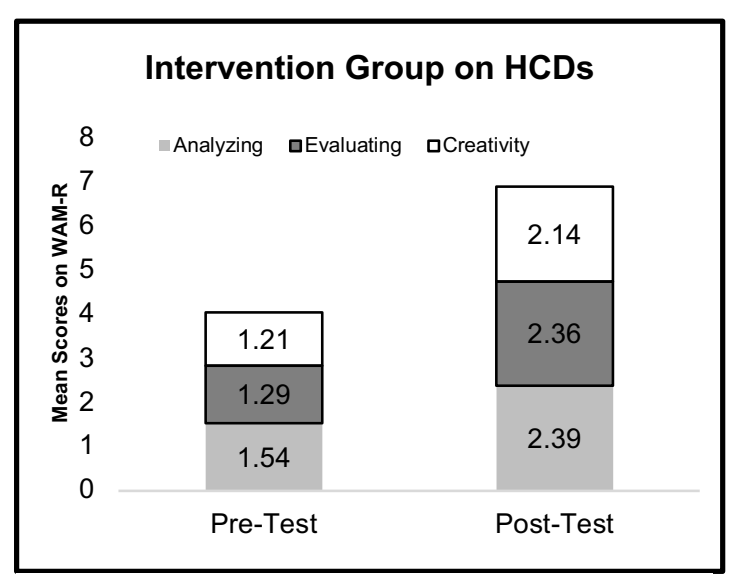

Figure 4. Performance of IG on HCD

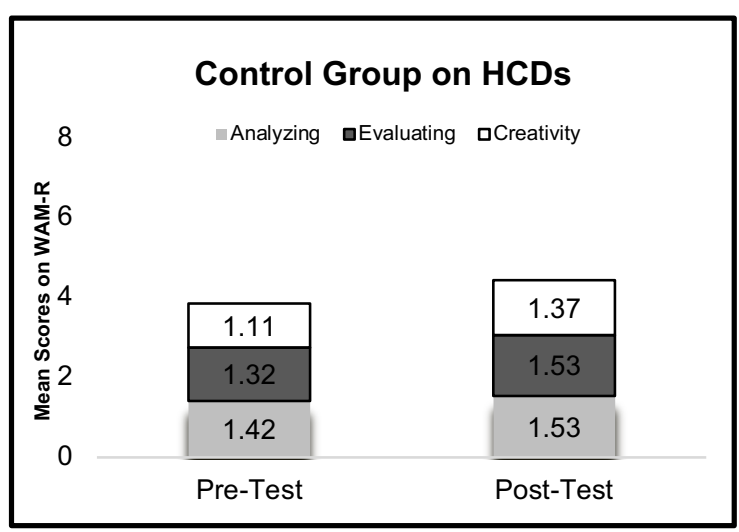

Figure 5. Performance of CG on HCDs 


\subsection{Performance on Higher Cognitive Domains (HCDs)}

Language elements in the HCDs include Organization and overall structure (Analyzing), Examining/Appraising/ critical thinking (Evaluating) and Ideas (Creating).

Both pre-test results on HCDs have shown similar performance of $\mathrm{CG}$ and $\mathrm{IG}$ which are statistically insignificant as well $(\mathrm{U}=240.500, \mathrm{z}=$ $0.09, p>0.05)$. It is evident from the post test results that PBL as significantly affected the HCDs ( $\mathrm{U}=$ 117.000, $\mathrm{z}=-3.288, p=0.001)$ with a medium effect size of 0.47 . On the whole, PBL as an instruction method facilitated more in higher order thinking domains in comparison to the lower order thinking domains. It was also revealed that lower order thinking was improved even in the traditional teaching instruction, where CG showed progress in remembering, understanding and applying. However, seeing the progress of IG in HCD implies that PBL is more effective for HCDs along with the LCDs.

Project based learning involves some amount of direct teaching as conducted in the traditional method. The process aims to provide sufficient background information about a topic or area. The extended part of the teaching (leading towards scaffolding) comes where students are asked to actually apply the knowledge in order to develop an artifact of their own choice. This is the stage that brings a difference in the learning graph of students, and where they receive an opportunity to reach higher levels of cognition.

Figure 4 illustrates the significant effect of PBL on the HCDs of IG participants, accounting for $70 \%$ improvement. The results infer that working on an end product of their own choice pitched at a real audience challenges them to use their critical and problem solving skills along with analyzing and evaluating each step to create a unique project. The chosen project provides confidence to the students to challenge ideas and not to accept everything on its own. On the other hand, traditional teaching method brought only $15 \%$ improvement in CG participants on HCDs inferring lack of opportunities for the participants to recycle knowledge and skills of language in any form (see Figure 5).

According to the findings, the overall performance of students taught by PBL $(\mathrm{M}=18.07, \mathrm{SD}=6.104)$ was better in English language writing skills, focusing on narrative writing, as compared to those students who were taught by $\mathrm{TM}(\mathrm{M}=11.95, \mathrm{SD}=5.437)$ with $\mathrm{U}=105.000, \mathrm{z}=-3.507 \mathrm{p}=0.00$ with the medium effect size of 0.5 . Moreover, PBL has affected all the cognitive domains as evident in the post test results benefitting understating in the LCD and, analyzing and critical thinking (evaluating) in the HCD the most.

Pre-test scores revealed the IG mean scores (28\%) were marginally higher than the CG $(24 \%)$ but were not significantly different $(p>0.05)$. The mean scores depicted that both groups were holding similar competencies and skills in terms of narrative writing. Both groups improved their mean scores on WAM-R $(\mathrm{CG}=30 \%, \mathrm{IG}=45 \%)$ in the post test revealing, that the respective instruction method has facilitated in improving narrative writing skills. Figure 6 illustrates the overall progress of students on WAM-R. On the other hand, it is noteworthy to observe that PBL brought $63 \%$ improvement in the overall scores of IG while TM brought only $22 \%$ improvement. Moreover, the difference in the scores of IG and CG were statistically significant $(p<0.05)$.

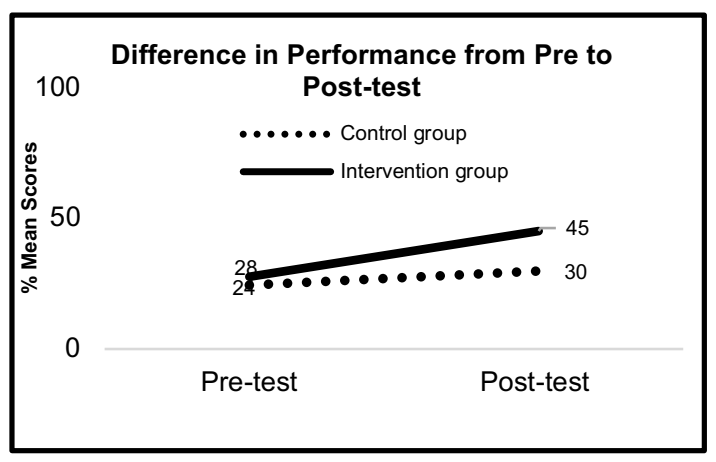

Figure 6. Difference in performance form pre to post-test

The analysis directs towards the routine practice of schools in the context of Pakistan that keep writing related exercises of EFL, reserved till the end of the academic year. Even though students receive a lot of exposure on various elements of language such as punctuation, verb tenses, kinds of sentences, use of articles, active/passive voice, etc., they do not receive sufficient time to apply all the language mechanics in the form of their own writings during the academic year. It is evident from the results that the Intervention group was able to produce better results as it was provided with ample opportunities to recall, understand, and apply (even create) various language concepts in their writings. Moreover, working in groups encouraged social learning (less focused in traditional method) where students worked as peers, helped each other in providing feedback, and improving their own work alongside.

\section{Discussion}

PBL is beyond simple incorporation of Projects [23]. Therefore, diligently incorporating all the elements of PBL in the classroom makes it a productive instruction method. In current study, Authenticity, Scaffolding Instruction, Pace of the project, and application of FACTs came out as the reasons for its effectivity against the traditional method. 
Besides working on a challenging question that involved students' voices and choices; authenticity of the project was one of the core reason for success of the intervention. Authenticity in classroom enables students to stay motivated on, ensure deeper engagement in the task and show visible improvement in learning [12]. The authentic nature of the task pushed students to apply their lower level cognition, utilizing their previous knowledge and language. Alongside, receiving opportunities to gradually move towards the higher cognition levels. It was an exciting idea for students to work as story writers knowing that their stories will be read by the people they know (grade 5 students of their own school). The authenticity of the project encouraged them to utilize their critical skills in identifying the reading interests of their target audience. Element of authenticity in PBL is supported in various researches [9], [11], [13] emphasizing that working and presenting to an authentic audience makes the task meaningful for the students.

The journey of cognitive apprenticeship begins when a teacher enacts scaffolding Instruction. Scaffolding instruction become one of the reasons for the participants of IG to utilize their teacher's consistent motivation, support, and feedback in exploring their imagination, associating rationale, and arguing constructively with peers thus, climbing more levels of higher cognition. As evident from the post test results, IG participants were able to showcase $70 \%$ improvement in the HCDs as compared to their $61 \%$ improvement on LCDs. Furthermore, scaffolding instruction also accommodated students' voices and choices and believed in distributing autonomy to the students encouraging them to think creatively.

It is debatable in the application of PBL about the optimum time that should be given to the students to work on the project as projects often take longer than anticipated [9]. Although as definition, a project can be placed for one week, one month or even for an entire academic year [23]. However, the significant effect $(\mathrm{r}=0.5)$ of the intervention signals that the utilized time of one month was an acceptable pace of the project, for the students to be provided with the comprehensible input on narrative writing and giving them enough time to produce a comprehensible output. It suited the individual needs and diverse modes of learning, providing sufficient time for the students to learn, apply, reflect, and create. Moreover, there were instances felt by the researcher where students were showing signs of boredom as they wanted to visualize the sense of achievement with the final product. Moreover, it is usually observed that students between 11-15 years old cannot show greater attention span and consistency on longer tasks. The interpretation of the optimum time cannot not be generalized to all PBL activities and therefore should be left to the discretion of the users.
To work through the idea of project-based learning; lesson plans were integrated with some Formative Assessment Classroom Techniques (FACTS). Theoretical framework of PBL emphasized the need of students to evaluate their learning at every stage of the project [14]. Moreover, formative [and summative] feedback to students enables them to monitor their own learning graph. Although, FACTs were integrated with both of the groups, its outcome was different for each group. In Traditional Method, participants of $\mathrm{CG}$ were able to monitor their individual learning for that session only while for participants of IG, it became an opportunity to create links between their learning and their task of developing the final artefact. Additionally, FACTs served as a small-scale reflection exercise where IG students were scrutinizing their own perceptions towards their writing skills. Students were recalling and applying all the knowledge and understanding that they had attained in the process on the development of the final product. The effect of FACTs can be linked with the performance of IG participants under comprehension $(\mathrm{r}=0.49)$ as their understanding levels were growing due to their exposure with FACTs.

Results of the undertaken study provide certain implications for the for the language teachers in Pakistan. Before PBL implementation schools may opt to bring significant changes in teaching and learning methods that may be helpful in smooth launch of PBL in the classroom. Firstly, the school may encourage the reading culture so students may internalize writing by developing reading habits. Secondly, as it was evident from the current study that the students are not habitual of working in groups and therefore, it takes time to build the group dynamics. Letting students work in groups in language classes would encourage collaborative learning, crucial for learning English as a foreign language.

All and all, to lead towards the path of progressive education (much needed for the educational system in Pakistan), the current pace of knowledge demands to think beyond correct and straight answers. Students must be encouraged to inquire and bring out their creativity in looking for possible answers. This is only possible when the belief system of potential PBL teachers of Pakistan's educational system is aligned with the ideology of PBL.

\section{Recommendations}

Undertaken study was a small-scale experiment that explored the effect of project-based learning on the writing skills. However, it is wider understood in the academia [6] [11] that PBL is not limited to language instruction and can be initiated as an interdisciplinary instruction method where projects combine two or more subject domains. 
Besides impacting lower and higher cognitive domains of content areas, PBL is an effective instruction method that improves collaborative, social and cooperative skills in students [23]. Moreover, PBL is believed to bring change in students' attitudes, self-confidence, self-esteem and self-initiation, and therefore, a study exploring change in students' social skills, behaviors and attitudes due to PBL is also suggested.

\section{Conclusion}

The study generated profound evidences of Project Based Learning being an effective method of instruction in comparison to Traditional Method of Language Learning in improving narrative writing skills of Grade 8 students based in the private school setup in Karachi. Moreover, the effectivity of PBL was revealed in both lower and higher cognitive domains of language elements. PBL has received plenty of endorsement from ESL/EFL as well as practitioners of other content areas across the globe.

It is the high time for the educationalists in Pakistan to endorse innovative and non-traditional instructions methods like PBL; that can strengthen our teaching and learning aims, motivate students to gain expertise in the EFL and ensure attaining successful personal and professional growth for our youth. PBL is now attaining popularity because of the benefits it offers. However, it must not be treated like a bandwagon that every school jumps in without clear guidance and adequate preparation.

\section{References}

[1] Rahman, T., (2014). Pakistani English (2nd ed.). Islamabad: National Institute of Pak Studies-Quaid-i-Azam University.http://www.tariqrahman.net/content/pakenglish. pdf_(Access Date: 06 June, 2015).

[2] Coleman, H., and Capstick, T., (2012). Language in education in Pakistan: Recommendations for policy and practice. Islamabad: British Council.https://www.teaching english.org.uk/article/language-edu-cation-pakistanrecommendations-policy-practice (Access Date: 15 June, 2015).

[3] Dunsmuir, S., Kyriacou, M., Batuwitage, S., Hinson, E., Ingram, V., and O'Sullivan, S., (2015). An evaluation of the Writing Assessment Measure (WAM) for children's narrative writing. Assessing Writing, 23, 1-18.

http://dx.doi.org/10.1016/j.asw.2014.08.001 (Access Date: 05 December, 2015).

[4] Dewey, J. (1938). Experience and education. New York, NY: Macmillan (Access Date: 02 February, 2015).

[5] Fried-Booth, D. L., (1986). Project work. Oxford: Oxford University Press. (Access Date: 16 December, 2015).
[6] Tamim, S., and Grant, M., (2013). Definitions and Uses: Case study of teachers implementing Project-based learning. The Interdisciplinary Journal of Problem-Based Learning, 7(2), 72-101. https://doi.org/10.7771/15415015.1323 (Access Date: 30 September, 2015).

[7] Neo, M., and Neo, T.-K., (2009). Engaging students in multimedia-mediated Constructivist learning - Students' perception. Educational Technology \& Society, 12(2), 254266 (Access Date: 07 May, 2015).

[8] Blumenfeld, P., Soloway, E., Marx, R., Krajcik, J., Guzdial, M., and Palincsar, A., (1991). Motivating Project based learning: Sustaining the doing, supporting and learning. Educational Phycologist, $26(3$ and 4), 369-398. http://dx.doi.org/10.1080/00461520.1991.9653139 (Access Date: 04 June, 2015).

[9] Thomas, J., (2000). A review of research on projectbased learning. California, CA: The Autodesk Foundations. http://www.bobpearlman.org/BestPractices/PBL_Research .pdf (Access Date: 07 May, 2015).

[10] Hovey, K. A., and Ferguson, S. L., (2014). Teachers' perspectives and experiences: Using Project based learning with exceptional and diverse students. Curriculum and Teaching Dialogue, 16(1\&2), 77-90 (Access Date: 14 April, 15).

[11] Laur, D., (2013). Authentic learning experiences: A real-world approach to project-based Learning. New York: Routledge. (Access Date: 14 April, 15).

[12] Larmer, J., and Mergendoller, J., (2015). Why we changed our model of the "8 Essential Elements of PBL". Buck Institute for Education. http://bie.org/object/document /why we changed our model of the 8 essential elemen ts_of_pbl (Access Date: 11 April, $\overline{2} 01 \overline{6}$ ).

[13] Lenz, B., Wells, J., and Kingston, S., (2015). Transforming schools: Using project based learning, performing assessment, and common core standards. San Francisco, CA: Jossey-Bass (21 June, 2015).

[14] Stoller, F., (2002). Project work: A means to promote language and content. In C. Richards, \& A. Renandya (Eds.), Methodology in language teaching: An anthology of current practice (pp. 107-120). New York, NY: Cambridge University Press (08 Feb, 2016).

[15] Beckett, G. H., (2006). Project-based second and foreign language education: Theory, research, and practice. In G. H. Beckett, and P. C. Miller (Eds.), Project-based second and foreign language education: Present, past, and future (pp. 3-14). Greenwich, CT: Information Age Pub. (Access Date: 21 June, 2015).

[16] Jacobson, J., and Lapp, D., (2010). Revisiting Bloom's taxonomy: A framework for modeling writing and critical thinking skills. The California Reader, 43(3), 32-47. http://www.ibaroudy.ir/bookcontent/Baroudy's\%20Work\% 20Cited\%2022.pdf (Access Date: 21 June, 2015).

[17] Rousseau, J. J. (1979). Emile: or, on education. New York, NY: Basic Books (Access Date: 02 February, 2015). 
[18] Piaget, J. (1954). The construction of reality in the child. New York, NY: Routledge (Access Date: 02 February 2015).

[19] Cunningham, D. J., and Duffy, T. M., (1996). Constructivism: Implications for the design and delivery of instruction. In D. J. Cunningham, T. M. Duffy, and D. Jonassen, (Ed.), Handbook of research for educational communications and technology (pp. 170-198). New Jersey, NY: Lawrence Erlbaum Associates. (Access Date: 11 April, 2015).

[20] Kintsch, W. (2009). Learning and constructivism. In T. Sigmund, \& T. M. Duffy (Eds.), Constructivist instruction: Success or failure (pp. 223-241). New York, NY: Routledge (Access Date: 07 May, 2015).

[21] Hmelo-Silver, C., Duncan, R., and Chinn, C., (2007). Scaffolding and achievement in problem-based and inquiry learning: A response to Kirschner, Sweller, and Clark (2006). Educational Psychologist, 42(2), 99-107. doi:10.1080/00461520701263368 (Access Date: 05 Dec, 2015).

[22] Papert, S., and Harel, I., (1991). Situating constructionism. Constructionism, 36, 1-11 (Access Date: 07 May, 2015).

[23] Stoller, F., (2006). Establishing a theoretical foundation for project-based learning in second and foreign language contexts. In G. H. Beckett, and P. C. Miller (Eds.), Project-based second and foreign language education: Past, present, and future (pp. 19-40). Greenwich, CT: Information Age Pub (Access Date: 08 February, 2016).

[24] Ministry of Education (Curriculum wing). (2006). National Curriculum for English Language for class I-XII. Islamabad: Government of Pakistan http://bisep.com.pk/downloads/curriculum/Grades-IXII/pk_al_eng_2006_eng.pdf(Access date 11 May 2015) 


\begin{tabular}{|c|c|c|c|c|}
\hline 己. & 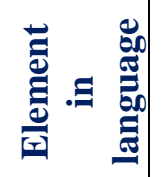 & Measuring Criterion & 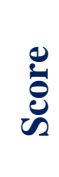 & $\begin{array}{c}\text { Evidences/ } \\
\text { Remarks }\end{array}$ \\
\hline \multirow{4}{*}{ 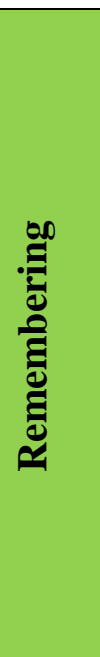 } & \multirow{4}{*}{ 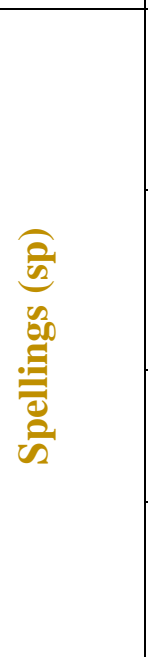 } & $\begin{array}{l}\text { Evidence of correct Spellings of complex words containing } \\
\text { prefixes/suffixes or irregular words e.g. souvenir, destruction and } \\
\text { conscious. }\end{array}$ & 4 & \\
\hline & & $\begin{array}{l}\text { Attempts to spell some complex or polysyllabic words using } \\
\text { phonetic strategies. E.g. 'Safariye' for safari, 'adventerous' for } \\
\text { adventurous. }\end{array}$ & 3 & \\
\hline & & $\begin{array}{l}\text { Spells the majority of high frequency common words correctly e.g. } \\
\text { inside, because, while. }\end{array}$ & 2 & \\
\hline & & $\begin{array}{l}\text { Spells some common monosyllabic words correctly e.g. mum, cat, } \\
\text { bird. Uses phonic strategies to attempt to spell high frequency } \\
\text { common words e.g. 'grat' for great, 'fhun' for fun. }\end{array}$ & 1 & \\
\hline \multirow{8}{*}{ 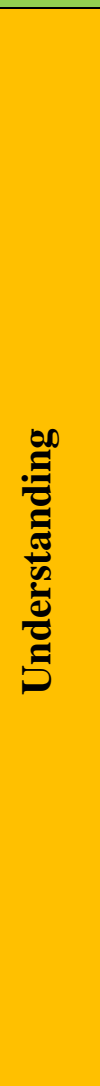 } & \multirow{4}{*}{ 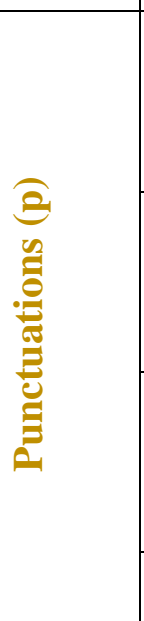 } & $\begin{array}{l}\text { Uses a range of punctuation to clarify structure and create effect } \\
\text { (e.g. Speech marks, dashes, brackets, apostrophes, commas to } \\
\text { demarcate sentences) }\end{array}$ & 4 & \\
\hline & & $\begin{array}{l}\text { Secure use of full stops and capital letters. Use Punctuation in } \\
\text { addition to capital letters and full stops, the majority are used } \\
\text { correctly (e.g. question marks, exclamations marks, commas in lists) }\end{array}$ & 3 & \\
\hline & & $\begin{array}{l}\text { Evidence of accurate use of capital letters and full stops, however } \\
\text { few there are. (e.g. Sentence finishes with a full stop and next } \\
\text { sentence begins with a capital letter) }\end{array}$ & 2 & \\
\hline & & Shows awareness of how full stops are used in writing. & 1 & \\
\hline & \multirow{4}{*}{ 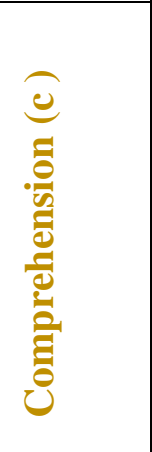 } & $\begin{array}{l}\text { Thoroughly understands what is expected to be written with respect } \\
\text { to the situation/topic/prompt etc }\end{array}$ & 4 & \\
\hline & & $\begin{array}{l}\text { Holds a clear idea what is expected to be written as a response to the } \\
\text { situation/topic/prompt with few deviations from the subject. }\end{array}$ & 3 & \\
\hline & & $\begin{array}{l}\text { Understanding of the topic is somewhat clear as depicted in few } \\
\text { places. }\end{array}$ & 2 & \\
\hline & & Understanding of the topic/situation/prompt is not clear at all. & 1 & \\
\hline \multirow{2}{*}{$\frac{e^{20}}{\frac{1}{2}}$} & \multirow{2}{*}{ 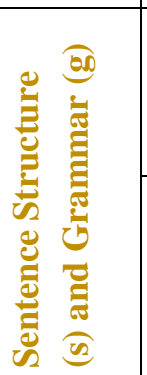 } & $\begin{array}{l}\text { Secure control of complex sentences. Understands how clauses can be } \\
\text { manipulated for effect. Able to use conditional and passive voice. (e.g. } \\
\text { having watched him eat a dog biscuit, she felt sick) }\end{array}$ & 4 & \\
\hline & & $\begin{array}{l}\text { Beginning to write extended sentences including subordinators (e.g. if, so, } \\
\text { while, when, after). The basic grammatical structure of sentences usually } \\
\text { correct (e.g. usually consistent and correct use of tenses and nouns and } \\
\text { verbs agree) }\end{array}$ & 3 & \\
\hline
\end{tabular}




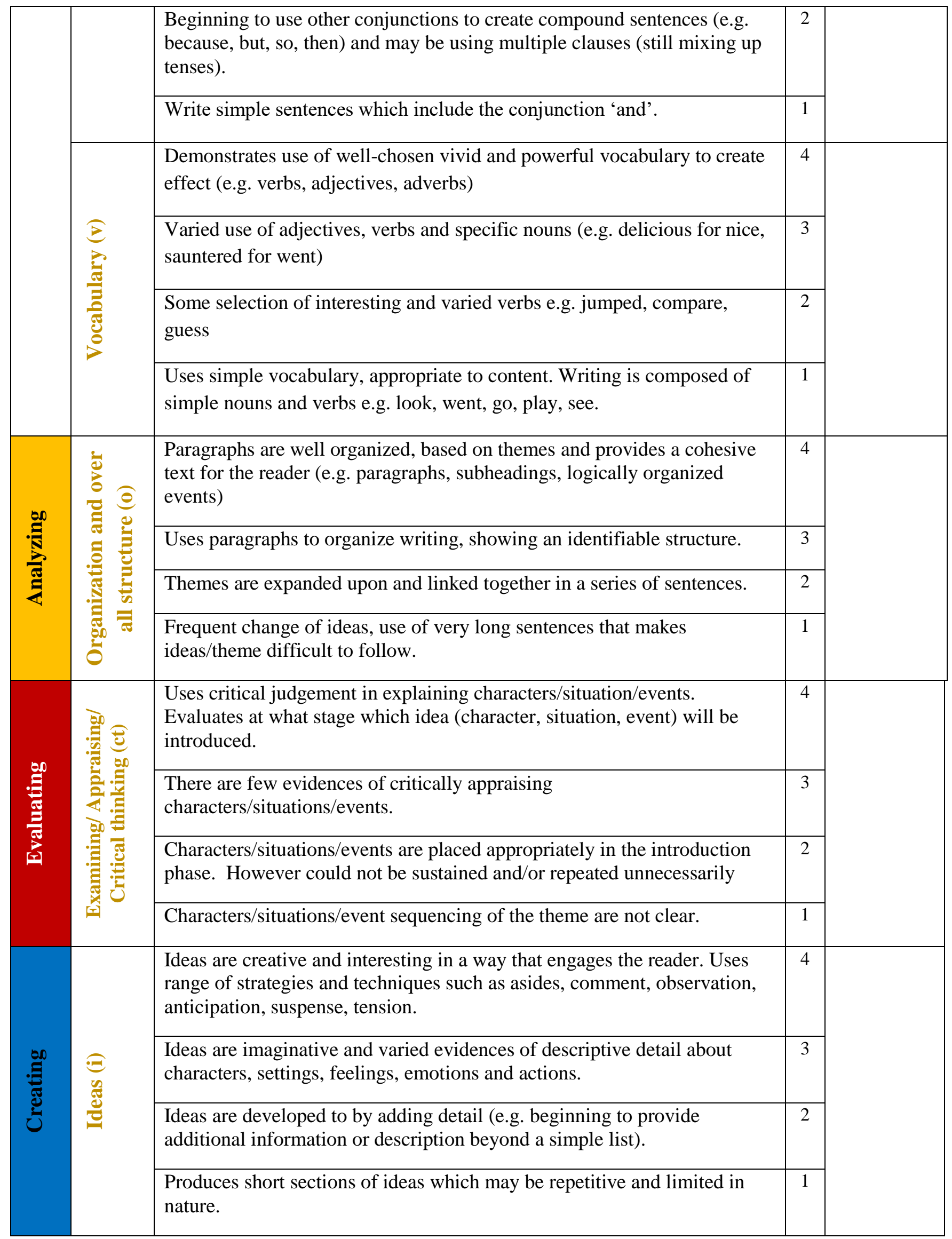

